\title{
Foreign Bodies in the Abdominal Area: Review of the Literature
}

\author{
Evangelos Nastoulis ${ }^{1, *}$, Maria-Valeria Karakasi ${ }^{1,2}$, Maria Alexandri ${ }^{1}$, Vasileios Thomaidis ${ }^{3}$, \\ Aliki Fiska $^{3}$, Pavlos Pavlidis ${ }^{1}$
}

\section{ABSTRACT}

The aim of this paper is to update and summarize the relevant literature on the anatomical localization, incidence, and diagnostic and therapeutic approaches to abdominal foreign bodies. A comprehensive review was carried out on recorded cases related to the presence of foreign bodies in the abdominal area throughout the literature. Moreover, the phenomenon was discussed in relation to different patient categories associated with childhood, mental or neurological illness, incarceration, and drug trafficking as well as sexual accident or abuse. Particular importance is ascribed to the underlying psychopathology and motivation of foreign body ingestion in each category of patients. The surgical, psychiatric and legal implications of the issue are discussed in detail.

\section{KEYWORDS}

foreign bodies; intra-abdominal; ingestion; surgery; endoscopy; pica; body packers; gossypiboma; forensic pathology; legal medicine

AUTHOR AFFILIATIONS

${ }^{1}$ Laboratory of Forensic Sciences, Democritus University of Thrace, School of Medicine, GR 68100 Dragana, Alexandroupolis, Greece

2 Third University Department of Psychiatry, AHEPA University General Hospital - Department of Mental Health, Aristotle University Faculty of Medicine, GR 54124 Thessaloniki, Greece

${ }^{3}$ Department of Anatomy, Democritus University of Thrace, School of Medicine, GR 68100 Dragana, Alexandroupolis, Greece

* Corresponding author: School of Medicine, Democritus University of Thrace, Dragana, 68100, Alexandroupolis, Greece; e-mail: nastevang@yahoo.gr

Received: 24 February 2019

Accepted: 14 July 2019

Published online: 30 October 2019

Acta Medica (Hradec Králové) 2019; 62(3): 85-93

https://doi.org/10.14712/18059694.2019.130

(c) 2019 The Authors. This is an open-access article distributed under the terms of the Creative Commons Attribution License (http://creativecommons.org/licenses/by/4.0), which permits unrestricted use, distribution, and reproduction in any medium, provided the original author and source are credited. 


\section{INTRODUCTION}

The presence of foreign objects (FB) in the abdomen may be due to involuntary or deliberate input orally or rectally. In addition, their misplacement can also be a result of iatrogenic complications during therapeutic interventions and surgical procedures. Furthermore, in some cases, foreign bodies, such as bezoars, can be gradually created in the lumen of the gastrointestinal tract.

Foreign objects that pass through the esophagus into the stomach and pylorus are automatically excreted in $80-98 \%$ of the cases, while only $1 \%$ of the aforementioned cases will cause perforation or other serious complications.

The presence of foreign bodies in the abdomen is a medical condition that employs multiple specialties, as, depending on the case, it constitutes a subject of general surgery, gastroenterology, gynecology, pediatrics, and psychiatry as well as forensic medicine and pathology.

In the present paper, the presence of foreign bodies is distinguished according to their characteristics (size, shape, type), anatomical localization, and differences in the diagnostic and therapeutic procedure associated with these parameters. Furthermore, the main population groups with an increased incidence of foreign bodies in the abdomen are reported (children, elderly, neurological patients, psychiatric patients, people with neurodevelopmental or neurodegenerative disorders, prisoners, and drug addicts), while particular incidents are also noted due to special clinical and forensic interest. The present thesis does not mention medical implants (foreign objects) placed in the abdominal area for therapeutic purposes. Incidents related to retained (forgotten) surgical items revealed after abdominal surgical procedures, however, are examined as well as risk factors, complications, prevention strategies, and forensic extensions related to the subject.

\section{METHODOLOGY}

A comprehensive review was carried out on recorded cases of the presence of foreign bodies in the abdominal area by searching the electronic data bases of PubMed, Google search, Google Scholar, Heal Link, EMBASE, Scopus, and Cochrane Library up to June 2018. The search terms were: "intra abdominal foreign bodies," "bezoars," "allotriophagy," "pica disorder," "retained surgical items," "gossypiboma," "body packers," and "foreign body ingestion." No language restriction was applied. All the articles have been evaluated and supplemented by searches of the bibliographies of key papers.

\section{RESULTS}

\section{ANATOMICAL LOCALIZATION OF FOREIGN BODIES} The most common anatomical sites of foreign body obstruction along the digestive tract are normal constrictions of the lumen, anatomical sphincters, acute angulations, curvatures, congenital deformities, tumors, or sites of previous surgical procedures that alter the anatomy of the area (e.g., adhesions or gastric rings).
In cases of foreign body ingestion, patients tend to seek help originally from the otorhinolaryngologist, as these patients tend to believe that the foreign body may be wedged in the hypopharynx or esophagus. The hypopharynx is a frequent area of bolus and foreign body retention. The situation is extremely urgent, as phenomena of asphyxiation often occur. After excluding the above, otolaryngologists guide patients to general surgeons, so that the foreign body can be detected and surgically removed if this procedure is assessed as appropriate (1).

\subsection{Foreign bodies in the gastric cavity}

Gastric foreign bodies usually do not induce any symptomatology. The presence of symptoms involving abdominal pain, fever, bleeding, or vomiting is indicative of complications such as pyloric stenosis, perforation, or rupture of the mucosa by a sharp foreign object (2).

The diagnosis is mainly based on history, $\mathrm{x}$-ray, and gastroscopy. Over $90 \%$ of swallowed objects progress along the entire digestive tract without complication within four to five days, while the majority of them pass though within 72 hours. Unless there are signs of obstruction, bleeding or perforation, an abdominal x-ray has to be performed daily so that the course of the subject can be monitored (1).

If the object is within the stomach, it can be removed endoscopically. The administration of laxatives is prohibited due to the high risk of intestinal perforation. In obstruction, bleeding, or perforation, surgical treatment is necessary (3).

Roughly, objects with a diameter of over $2.5 \mathrm{~cm}$ have a lower probability of passing through the pyloric canal, whereas objects of a length of 5-10 cm are unlikely to progress through the duodenal flexure, and therefore endoscopic or surgical removal is necessary within a week (1-3).

\subsection{Foreign bodies in the small intestine}

As mentioned above, foreign bodies with a length of at least $5 \mathrm{~cm}$ can be trapped in the duodenal flexure, in the area of the ligament of Treitz and the ileocecal valve. Obstruction or perforation by sharp objects most frequently occurs in the ileum and ileocecal valve.

Plain abdominal X-rays at regular intervals are useful for monitoring the course of ingested foreign bodies into the small intestine (as long as the objects are radiopaque and can be imaged). The presence of fever, pain, vomiting, meteorism, or bleeding signifies the presence of a complication. Endoscopic removal of foreign bodies in the small intestine is extremely difficult, and often even impossible, and thus, the usual therapeutic option is surgical intervention (4-5).

\subsection{Foreign bodies in the large intestine}

Foreign bodies in the colon and rectum may cause obstruction or perforation. Swallowed objects may be trapped in the caecum and ascending and sigmoid colon, while foreign bodies that have entered the intestinal tract through the anal canal are most frequently trapped in the rectum and sigmoid colon (6). 
Rarely, foreign bodies can also progress into the lumen of the appendix and cause obstruction, resulting into acute appendicitis (7). It should be noted, however, that the presence of a foreign body in the lumen of the appendix does not always lead to obstruction and direct inflammation. It is known that smooth and spherical objects, such as bullets, seeds, and others can create endoluminal formations, enteroliths that grow progressively and cause delayed appearance of inflammation (8). In cases of a foreign-body presence in the lumen of the appendix, it is also possible that acute appendicitis never develops (9). Nowadays, the prevailing view is that, if a foreign body that would be unlikely to regress in the intestine from the lumen of the appendix is found during a radiological examination, an on-the-spot appendectomy should be recommended.

In the presence of peritonitis, surgery is essential. In most cases of foreign body presence in the colon, endoscopic removal is feasible usually by means of suppressive medication, but general anesthesia may also be required. Enemas and laxatives are prohibited. Surgery is indicated if endoscopic removal fails (10).

\section{CLASSIFICATION OF FOREIGN BODIES}

BY MEDICAL IMAGING

(a) Organic chemical materials, low atomic weight $(<20)$ : for example, plant and flower thorns, woods, plastic, polyurethane, rubber, and fibers. These materials are not visible in simple X-rays, and are not usually observed in Computed Tomography (CT) scans, while they can be visualized by ultrasound or Magnetic Resonance Imaging (MRI) scans. Medical judgment and prudence are essential, however, for proper diagnosis (11).

(b) Low atomic weight metals (20-40): for example, aluminum (Al) and derivatives, such as aluminum nails, common glass, silicon $(\mathrm{Si})$, calcareous rocks, dirt, fish and meat bones. These materials are not easily displayed in plain X-rays and Computed Tomography (CT) scans, except by radiation adjustments, while, again, the diagnosis is uncertain. The aforementioned materials can be visualized more easily with ultrasound and Magnetic Resonance Imaging (MRI) (11).

(c) Metals of high atomic weight (>40): for example, iron $(\mathrm{Fe})$, nickel $(\mathrm{Ni})$, copper $(\mathrm{Cu})$, lead $(\mathrm{Pb})$, silver $(\mathrm{Ag})$, and gold $(\mathrm{Au})$. The most common objects containing the aforementioned materials are aluminum car sheets, specific glasses, other metal objects, steel pins, steel needles, remnants of metal processing, heavy metal soils (e.g. pyrite, and lead, etc.), and radiopaque construction materials. All of these materials can be observed in simple X-rays (11).

\section{ENDOSCOPIC TECHNIQUES \\ FOR THE REMOVAL OF FOREIGN BODIES: \\ INDICATIONS - CONTRAINDICATIONS - \\ COMPLICATIONS}

Endoscopic removal of foreign bodies from the digestive tract must be performed by an experienced endoscopist along with adequate nursing support. Initially, it is significant that the endoscopist confirms the non-existence of any evidence of blockage of the upper respiratory tract during the removal process of the foreign bodies. Respiratory tract obstruction is not a rare condition during the removal process.

The presence of foreign bodies in the upper digestive tract is a strong indication for endoscopic removal. The main complications of the endoscopic removal of foreign bodies from the gastrointestinal tract are mucosal ulcers, perforations, and bleeding (2). Contraindications to the endoscopic removal of foreign bodies are patients' inability to co-operate, acute esophagitis (e.g., due to ingestion of caustic substances), and stomach perforation as well as congenital or acquired gastrointestinal tract deformities.

\section{SURGICAL REMOVAL OF FOREIGN BODIES}

Ingestion of voluminous or sharp objects is a strong indication for surgical, rather than endoscopic, removal. In addition, if the foreign body has caused gastrointestinal perforation (signs of acute abdomen, abdominal wall contraction, fever, abscess, or pneumoperitoneum), the indication for surgical removal is absolute. Other surgical removal indications are the following: absence of an experienced endoscopist, failure of previously conducted endoscopic methods, constantly unaltered localization of the foreign body for 48-72 hours amidst the occurrence of abdominal symptomatology, or the ingestion of cocaine packs. Although the occurrence of gastrointestinal perforation by foreign bodies is rare, any foreign object after perforating the gastrointestinal tract could make its way to any nearby abdominal organ. Throughout international literature, cases have been reported of foreign body migration from the gastrointestinal tract to the liver, pancreas, spleen, greater omentum, and mesenteric vessels (12-13).

\section{DISCUSSION}

\section{FOREIGN BODY INGESTION IN CHILDREN}

Infants and children have a natural propensity to assess and identify their surroundings, usually through touching, tasting and often swallowing new, unfamiliar, and bizarre items. This tendency of children to swallow anything they are able to put in the oral cavity renders swallowing of foreign bodies a common clinical condition in child populations, most frequently between the ages of six months and three years.

Among children with a history of gastrointestinal tract surgery due to congenital abnormalities (e.g., esophageal atresia or intestinal atresia), entrapment of the foreign body in areas of anastomosis and rupture is more likely to occur (14).

\subsection{Most frequently ingested objects in children}

In a retrospective statistical study of medical cases of foreign body ingestion in children spanning a period of 33 years (1964-1997), from the Pediatric Surgery Department of the University Hospital of Hong Kong, Cheng and others studied 525 incidents. The age of the children ranged from six months to 16 years (mean age 5.2 years), 
while pre-school age (mean age 3.8 years) was found most prone to foreign body swallowing. The most commonly confirmed cases of ingested objects from children (either through endoscopic or imaging procedures) were the following: coins $49 \%$, fish bones $29 \%$, other metal objects (batteries, sharp objects) 13\%, other bones $2.7 \%$, items of plastic $1.6 \%$, and glass $1.2 \%(15)$.

\subsubsection{Metal coins}

Metal coins contain $97.6 \%$ zinc and $2.4 \%$ copper, while they are the most commonly ingested foreign bodies among children. Zinc (atomic number 30) has corrosive properties, and its presence in a localized anatomic area for a long time could cause rupture. In addition, if a large quantity of coins is swallowed, severe poisoning may result, leading to death.

In children, coins with a diameter of less than $2 \mathrm{~cm}$ are usually propelled by peristalsis into the small intestine, while those with a diameter larger than $2.5 \mathrm{~cm}$ are unable to move further and need to be removed (14-15).

\subsubsection{Metal disc-shaped batteries}

The increased use of disc-shaped batteries in various household electronic devices, due to their small dimensions, has resulted in the increased incidence of their ingestion by children, and thus in the increased incidence of esophageal caustic injury in children. Batteries with a diameter of less than $20 \mathrm{~mm}$ are promoted along the gastrointestinal tract and are excreted naturally. Larger diameter batteries are usually trapped in the esophagus or gastric cavity. Their harmful effect on the tissues mainly in the esophagus is due to three mechanisms: a. pressure necrosis, b. low voltage electrical current, and c. release of their alkaline content causing necrosis and rupture (16). If batteries are not eliminated within five days' time or abdominal symptoms begin to develop (abdominal pain, peritoneal irritation), surgical removal is necessary $(14,16)$.

\subsubsection{Sharp and long objects}

Ingestion of sharp objects of a length greater than $5 \mathrm{~cm}$, such as long needles, pins and toothpicks, is associated with increased morbidity and mortality, as it accounts for 15$35 \%$ of rupture occurrence due to foreign body ingestion. According to the relevant guidelines, in general, ingested objects longer than $5 \mathrm{~cm}$ ( $3 \mathrm{~cm}$ in small children) or greater than $2 \mathrm{~cm}$ in diameter, which are localized in the stomach, have to be surgically removed before being promoted into the intestine. The ingestion of smaller objects, such as small screws, small nails, and pins, can be conservatively treated with monitoring, as they are often excreted naturally (14).

\section{FOREIGN BODY INGESTION IN PSYCHIATRIC AND NEUROLOGICAL PATIENTS}

Among patients suffering from psychiatric and neurological disorders (myotonic dystrophies, Guillain-Barré syndrome, and Parkinson's disease), the presence of bezoars in the gastrointestinal tract is often revealed. Bezoars comprise foreign material concentrations in the di- gestive system (especially in the gastric cavity). Bezoars are distinguished into the following types: a. phytobezoar; b. trichobezoar; c. lactobezoar (in premature infants); d. pharmacobezoar (due to medications with cholesteramine, sulfrafate, nifedipine, or antacids); e. other bezoars (trichophytobezoar, diospyrobezoar, and bezoar due to dead parasitic worms - ascaris or Toxocaracati (17).

In addition to mental or neurological disease, other predisposing factors for the formation of bezoars are the following: a. gastrectomy or vagotomy and pyloroplasty (5-12\% in patients with a history of gastric operations); b. endocrinopathies (diabetes mellitus and hypothyroidism); c. other factors (cystic fibrosis, cholestasis, kidney failure, and inadequate chewing) (17).

Bezoars are a rare cause of occlusive ileus at a rate of $0.4-4 \%$. Preoperatively, the diagnosis can be set via ultrasonography in $88 \%$ of cases, as an echogenic mass with acoustic shadowing. When bezoars are localized within the gastric cavity, the treatment is focused on enzymatic cleavage or endoscopic fragmentation. In the case of obstructive ileus, laparotomy is preferable for the promotion of the bezoar through the ileothyphal valve into the large intestine, or removal of it by intestinal incision close to the obstructed site.

Rapunzel syndrome is a rare and unusual form of thrichobezoar extending from the stomach to the small intestine. It usually occurs in young female individuals with a history of psychiatric disorders with signs and symptoms of gastrointestinal obstruction or malabsorption and requires surgery by laparotomy or laparoscopy (18).

Another trait of psychiatric patients is the ingestion of multiple objects simultaneously or repeatedly (19-20).

In addition, patients with mental disorders are likely to experience allotriophagy (Pica disorder). As allotriophagy (from allo- meaning "different" and -phagy meaning "eating") is defined as the compulsive unrelenting desire of an individual to consume, that is, to eat or chew items that are not edible or non-nutritional. Such consumed items may be metal objects (metallophagia), pieces of wood or paper (xylophagia), soil or sand (geophagia), stones (lithophagia), glass (hyalophagia), ice (pagophagia), hair (trichophagia), feces (coprophagia), cigarette residues, ash, toothpaste, or soap (21).

This disorder is included in the category of "eating disorders" of ICD-10-and DSM, and is more common in individuals with mental disorders, impaired functioning (e.g., schizophrenia spectrum disorders or obsessive compulsive spectrum disorders), neurodevelopmental disorders (e.g., autism spectrum disorders), during medical conditions (e.g., pregnancy), and, in small children, due to lower developmental level. (21-22).

As the damage that this disorder can cause to an individual's health is often irreparable, patients that suffer from Pica disorder have to be examined by a psychiatrist for treatment and prevention (23).

A specific category of allotriophagy, as mentioned above, is xylophagia. Within international bibliography, a fatality was reported involving an individual who was suffering from schizophrenia, had been multiply hospitalized in psychiatric units, and was in treatment with antipsychotics (clozapine) and antidepressants (citalopram and mirtazapine) (24). 


\begin{tabular}{|c|c|c|c|c|c|c|c|c|}
\hline 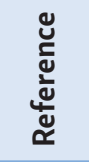 & 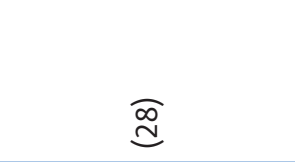 & ఏ్త & 忢 & 产 & 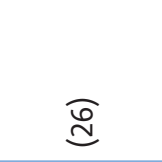 & $\widehat{\vec{m}}$ & $\underset{\widetilde{\rho}}{\widetilde{\sigma}}$ & $\widehat{\widetilde{m}}$ \\
\hline 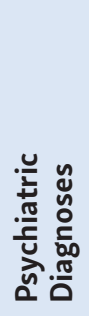 & 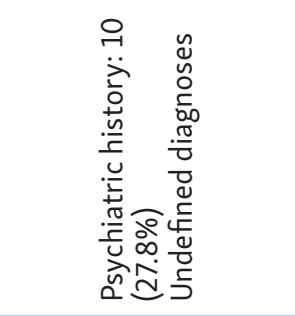 & 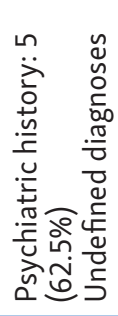 & 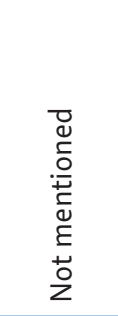 & 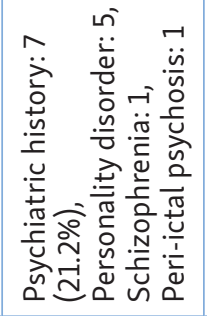 & 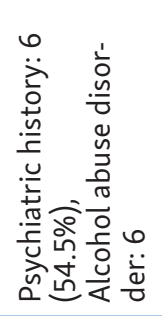 & 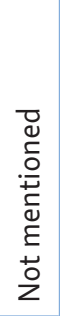 & 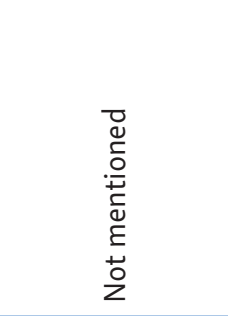 & 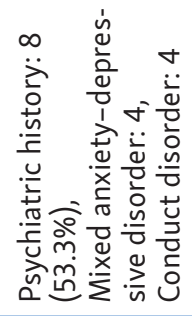 \\
\hline 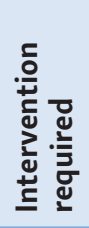 & 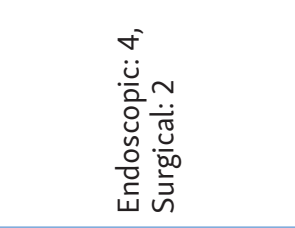 & 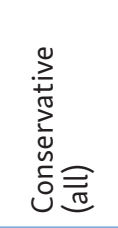 & 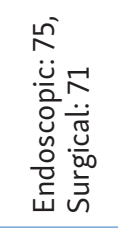 & 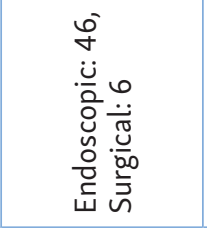 & 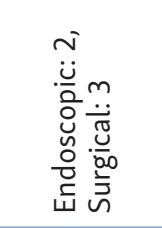 & 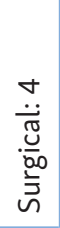 & 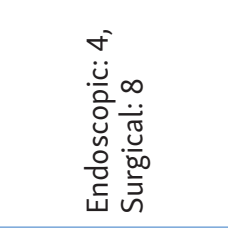 & 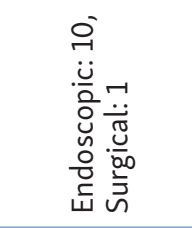 \\
\hline 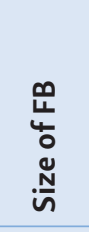 & 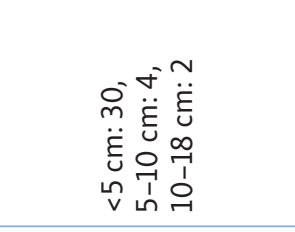 & 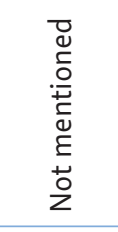 & 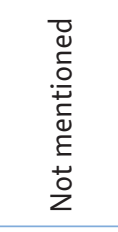 & 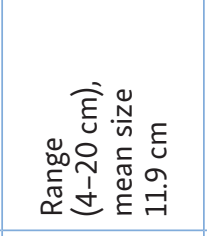 & 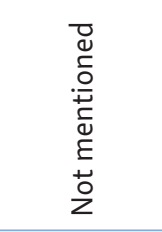 & 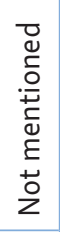 & 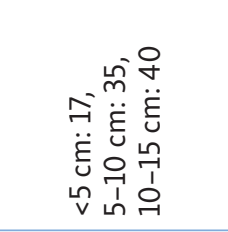 & 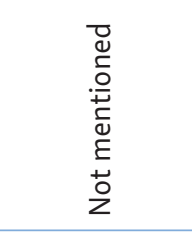 \\
\hline 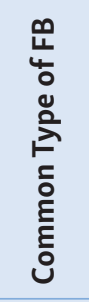 & 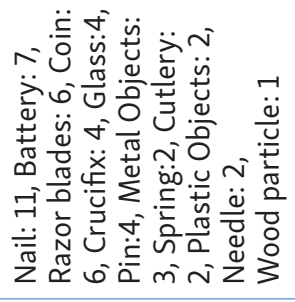 & 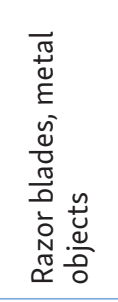 & 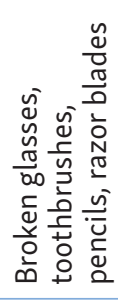 & 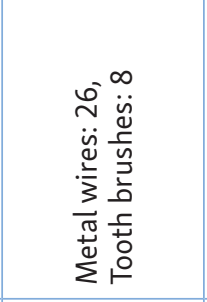 & 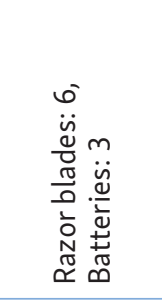 & 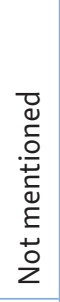 & 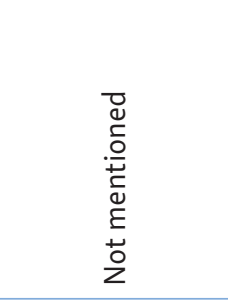 & 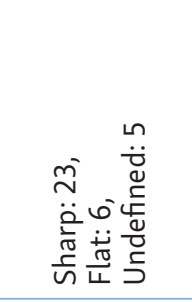 \\
\hline 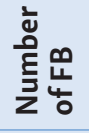 & กิ & $\underset{\sim}{J}$ & $\stackrel{\mathscr{N}}{\sim}$ & กิ & $\stackrel{\mathscr{N}}{\sim}$ & $a$ & $\stackrel{\text { L }}{\circ}$ & $\stackrel{\nabla}{m}$ \\
\hline 일 & 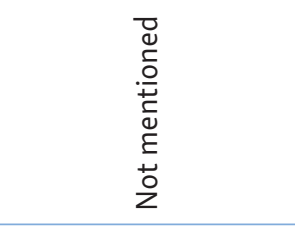 & 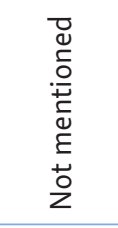 & 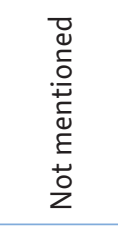 & 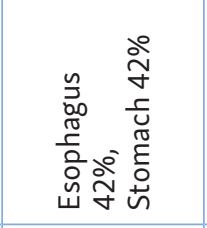 & 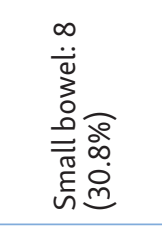 & 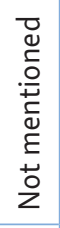 & 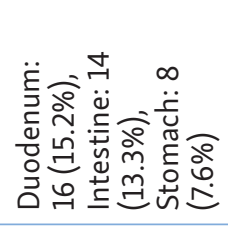 & 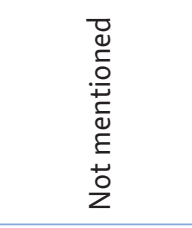 \\
\hline 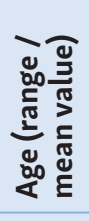 & 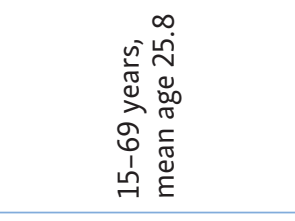 & 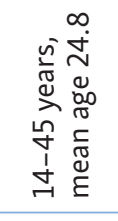 & 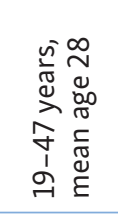 & 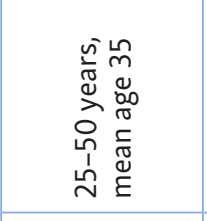 & 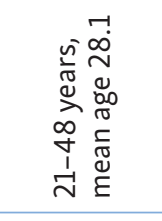 & 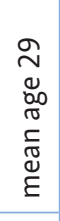 & 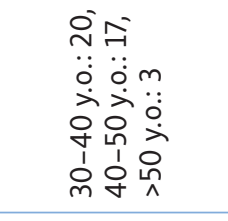 & 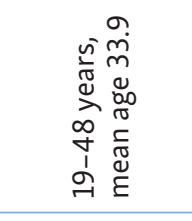 \\
\hline 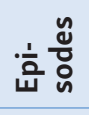 & กิ & $\underset{ন}{\Delta}$ & 읏 & กิ & $\stackrel{\bullet}{\sim}$ & $a$ & 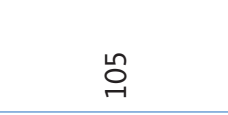 & $\vec{\lambda}$ \\
\hline 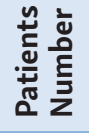 & $\stackrel{m}{m}$ & $\infty$ & $\approx$ & $\stackrel{m}{m}$ & $F$ & $a$ & $\stackrel{\text { ำ }}{\forall}$ & $\stackrel{\sim}{\sim}$ \\
\hline 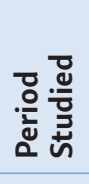 & 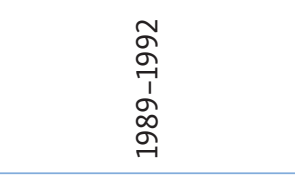 & 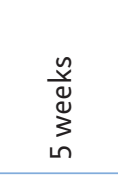 & 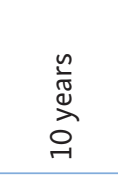 & 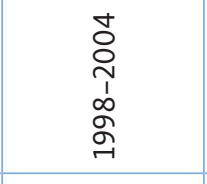 & 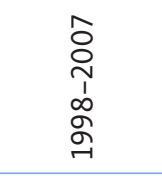 & 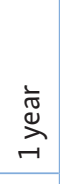 & 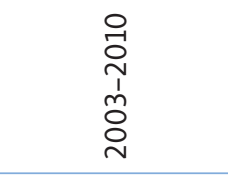 & 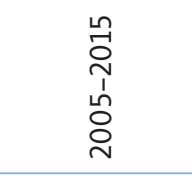 \\
\hline $\begin{array}{l}\vec{i} \\
\stackrel{\vec{z}}{0}\end{array}$ & 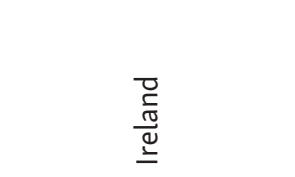 & 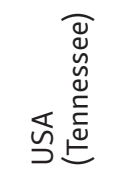 & 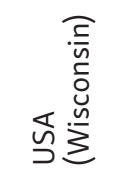 & 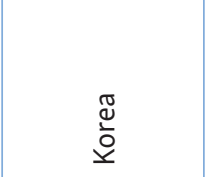 & 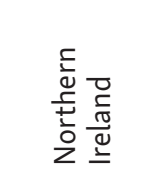 & 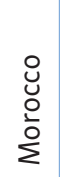 & 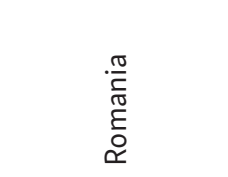 & $\stackrel{\overrightarrow{ \pm}}{\underline{ \pm}}$ \\
\hline
\end{tabular}




\section{FOREIGN BODY INGESTION IN PRISONERS}

The voluntary ingestion of objects is a common tactic among prisoners, but with varying underlying motivations. The most common aim of prisoners is to avoid incarceration or be transferred to nursing homes or psychiatric units. Sometimes, however, this may be due to undiagnosed mental disorders (schizophrenia spectrum disorders, depressive disorder, or suicidal actions), and, in other cases, as a way of trafficking drugs or other objects (25). In a study conducted at a hospital in Northern Ireland that treated emergency cases from the Belfast prison during the period 1998-2007, 11 cases of foreign body ingestion by prisoners were recorded (26). A characteristic observation is that while, in the general population, foreign bodies are usually automatically excreted, and only a very small percentage of the cases require medical intervention, in prisoners, the portion of cases requiring medical intervention is relatively higher. In the above-mentioned study, statistical results indicated that $36 \%$ of the prisoners needed surgical or endoscopic intervention (18\% laparotomy, $9 \%$ endoscopy, and $9 \%$ both endoscopic and surgical procedures). The same conclusion was reached by another study by Weiland and his colleagues in Wisconsin, USA, in which $30 \%$ of foreign bodies were removed by surgery (27). The following table depicts all studies examining cases of voluntary ingestion of objects among prisoners throughout the literature (Table 1). A history of foreign-body ingestion prior to incarceration is very rare. The phenomenon usually begins during imprisonment and is often recurrent, followed by considerably high costs for the national health system. The psychological examination of prisoners with a history of intentional swallowing of foreign objects reveals high levels of psychopathology as well as antisocial and impulsive behavior, usually within the spectrum of personality disorders. High levels of suicidal ideation, however, have been identified among prisoners who engage in voluntary ingestion of objects (28).

\section{FOREIGN BODIES IN DRUG ADDICTS - \\ "BODY PACKERS"}

Throughout the literature, men, women, even pregnant women, and a minor have been recorded as body packers. In particular, a 12-year-old boy in the USA had been found to be carrying 84 packets of heroin in his gastrointestinal tract. Professional body packers most often swallow drug packs, sometimes import them rectally into the gastrointestinal tract, and, in other cases, carry them in the vagina (34). When they are admitted to the hospital, in cases of package rupture, the following clinical symptoms are usually present: hyperthermia, hypertension, tachycardia, mydriasis, epileptic seizures, or status epilepticus, delirium, lethargy or coma. In some cases, even fatalities have been reported as a result of acute poisoning by the transported narcotics (35). In a study by Schaper and colleagues, the research sample comprised 4660 individuals who were identified as body packers and were arrested at the airports in Frankfurt and Paris between 1985 and 2002. Of the aforementioned subjects, $1.4 \%$ (64 individuals) developed symptoms of acute poisoning from cocaine induced by package rupture (36).

\section{FOREIGN BODIES IN THE ABDOMINAL AREA AS} A RESULT OF SEXUAL ABUSE OR SEXUAL ACCIDENT Foreign body insertion and retention in the rectum may occur in adults during sexual activity or among sexually abused children (37). Throughout international literature, fatalities have even been recorded due to foreign body insertion into the rectum. In a literature review of autoerotic deaths by Sauvageau and colleagues, two deaths were reported due to abdominal foreign bodies (38). The first case involved a 56-year-old male who rectally inserted the heel of a woman's shoe, resulting in rectal perforation and profuse bleeding. In the second case, a 40-year-old male died as a consequence of peritonitis after the insertion of a pencil into the urinary bladder.

\section{PRESENCE OF NON-RECOLLECTED SURGICAL TOOLS / ITEMS IN THE ABDOMINAL AREA}

In the relevant literature, retained surgical items are defined by specific terms such as gossypiboma, textiloma, gauzoma, or muslinoma. The most widespread term is "gossypiboma," which derives from the Latin word "gossypium" meaning cotton, and the word "boma," which in Swahili means a "hiding point," and is used in the case where the forgotten object is a pad of absorbent material; a surgical gauze or compress (39).

Regarding the prevalence of this phenomenon, Lincourt and colleagues indicated that the majority of incidents associated with retained surgical items have been recorded in abdominal surgical procedures (46\%) (40). The incidence of retained, surgical-item cases ranged from 1 in 1,000-1500 intra-abdominal surgical interventions according to reports during the 1980 s, while results of modern epidemiological studies indicate a considerable drop in the incidence of the phenomenon to 1 in 5,500-18,760 surgical procedures (41-42). The aforementioned absolute figures may be underestimated, however, as they relate only to cases that eventually led to the court of justice (43).

Recent research has highlighted that the urgent nature of surgeries in specific cases comprises a key risk-factor for the retention of a surgical foreign body in the abdominal area, highlighting the fact that the relative risk increases almost nine-fold in comparison to regular surgeries (44). Other risk factors are summarized in Table 2.

Tab. 2 Risk factors for retained surgical items in the abdomen.

\begin{tabular}{|l|}
\hline Emergency nature of incident and surgery \\
\hline Complex surgical procedures \\
\hline Profuse bleeding \\
\hline Change of surgical strategy (unscheduled) \\
\hline Participation of various surgical subspecialties - groups \\
\hline High body mass index of the patient \\
\hline Prolonged operative duration \\
\hline High number of individuals in the operating room \\
\hline Shift or personnel changes \\
\hline Insufficient training \\
\hline Usage of an unusually large number of surgical gauzes \\
\hline Usage of small-sized surgical gauzes \\
\hline
\end{tabular}




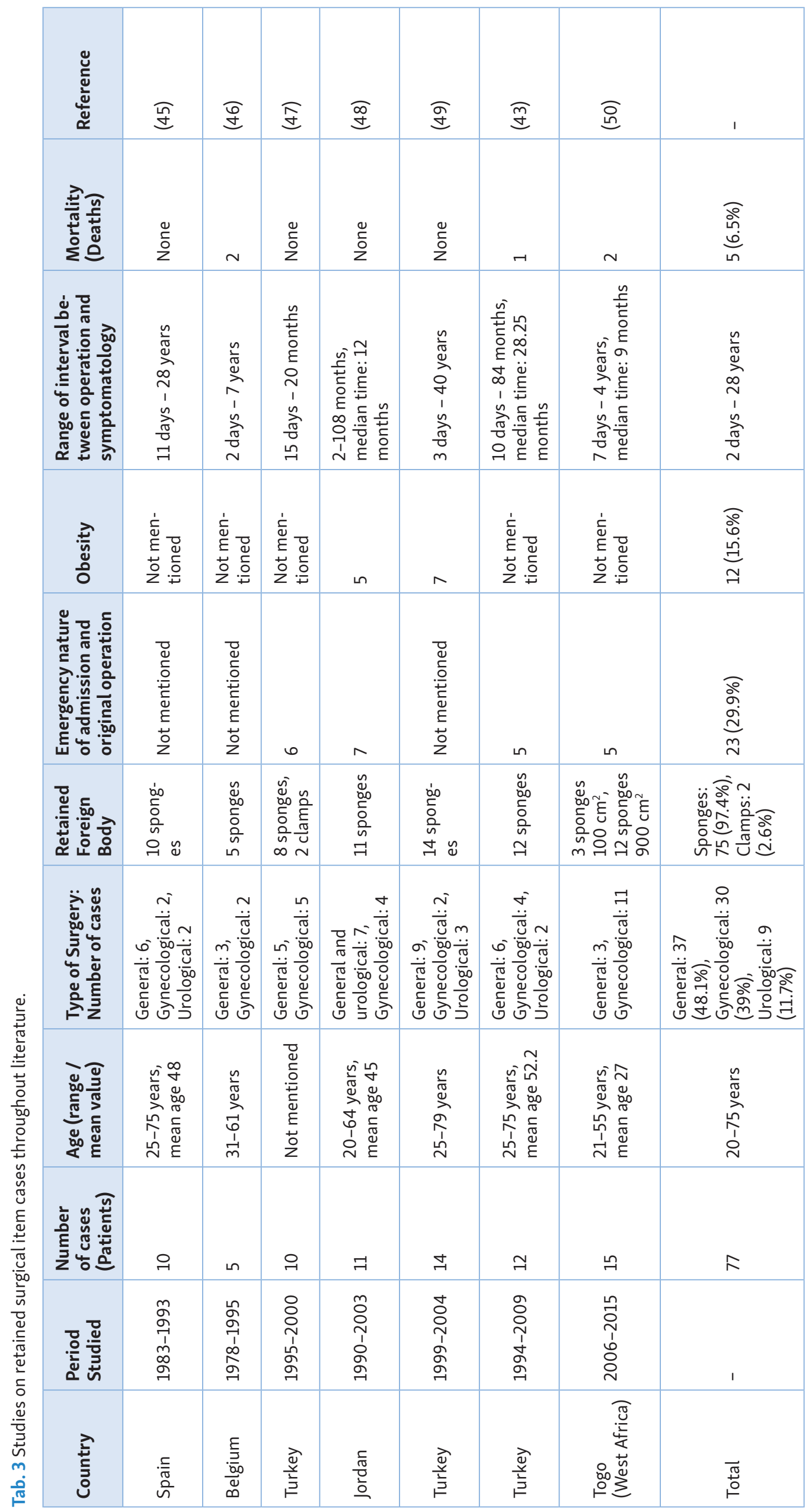


In a minor portion of the cases, retained surgical items remain asymptomatic without any complications and are usually identified randomly during postliminary medical examinations. Therefore, a retained surgical object may be detected in the ensuing several months or even years. The health condition of the affected patients can be significantly burdened, leading to adverse outcomes and even death in some cases (44) (Table 3).

According to statistics drawn from studies on cases of retained surgical items reported in detail throughout literature, approximately half (48.1\%) of the cases occurred in the context of general surgery procedures followed by gynecological - obstetrics surgeries (39\%). Urological surgeries were less frequent and tabulated at $11.7 \%$ of retained surgical item cases in the literature. Sponges (surgical gauzes) were the most frequently retained surgical items, accounting for $97.4 \%$ of the cases. In approximately onethird of the cases (29.9\%), the admission of the patient to the operating room was urgent (non-scheduled surgery), and $15.6 \%$ of the patients faced obesity issues. The onset of abdominal symptoms due to the retained surgical items was observed to range between two days (minimum) to twenty-eight years (maximum); 6.5\% of patients did not survive the complications.

The most common symptomatology due to retained surgical items includes pain (42\%), palpable mass, and fever. Other complications are reported in Table 4.

Tab. 4 Complications due to retained surgical items in the abdominal area.

\begin{tabular}{|l|}
\hline Abdominal pain not otherwise explained \\
\hline Presence of abdominal mass \\
\hline Intra-abdominal bleeding \\
\hline Abdominal organ perforation \\
\hline Intestinal obstruction \\
\hline Fistula formation \\
\hline Translocation to adjacent organ \\
\hline Sepsis \\
\hline Multiple complications (combination of the above) \\
\hline $\begin{array}{l}\text { Other (weight reduction, ileus, urinary retention, abdominal } \\
\text { distension, nausea, vomiting, fever of unknown origin) }\end{array}$ \\
\hline
\end{tabular}

In an article by Tumer and colleagues, ten cases were studied which were associated with retained surgical items after abdominal surgery having occurred in hospitals in Turkey during the period 1995-2000. All of the patients survived. In all patients, a second surgical procedure was performed so the retained surgical items could be successfully removed. All cases were taken to court, and, in all cases, there was a legal conviction. In seven cases, the surgeons who were found responsible were convicted, while in three cases the legal conviction concerned the entire surgical team (47).

The cost of compensation related to the retention of surgical items is high even if there is minimal or nonexistent current risk to the patient. The cost varies between $\$ 37,041$ and $\$ 2,350,000$ (US Dollars) (approximately $€ 31,754-€ 2,014,805$ euros) per incident, which is an average of $\$ 95,000$ or $€ 81,453$ per incident (42). Furthermore, in the majority of cases, there is conviction of the surgeonin-charge or the whole surgical team by court decision for medical error or malpractice, as retained instruments subsequent to surgery is a fully preventable and predictable cause of morbidity and mortality (43).

\section{CONCLUSION}

The presence of foreign objects in the abdomen may be due to their gradual formation in the lumen of the gastrointestinal tract, voluntary ingestion, rectal input, or iatrogenic input as a complication after surgical interventions. The presence of foreign bodies in the abdominal area is a medical condition that employs multiple specialties and requires high medical costs at a health system level, although the minority of cases do exhibit complications and require intervention.

The present review aims to update and summarize international literature on the presence, occurrence, anatomical localization, diagnosis, and treatment of gastrointestinal foreign bodies. The phenomenon is examined and discussed with respect to different groups of patients: children, psychiatric and neurological patients, prisoners, body packers, and postoperative patients (retained surgical items) as well as individuals subjected to sexual abuse or accident. To the authors' knowledge, there is no other multidisciplinary comprehensive review on the subject of foreign bodies in the abdominal area throughout international literature.

\section{DECLARATION OF INTEREST STATEMENT}

The authors report no declarations of interest. This work has not been funded by any corporation.

\section{ACKNOWLEDGEMENTS}

I would like to express my deep gratitude to the Cambridge Academic Editors Ms Kathleen Malone Hart (M.A., Anglo-Irish Literature, University College Dublin, Ireland) and Mr Robert Chatel (A.M., Philosophy, University of Chicago, USA) who helped us edit our manuscript with their collaboration and combined experience.

\section{REFERENCES}

1. Velegrakis G, Gelis D, Karatzanis A, et al. Emergency Otorhinolaryngology. Foreign bodies in the outer acoustic duct and stomach. Modern Otorhinolaryngology Update. Available at: https://www .iatrikionline.gr/Syxr_ORL_1_07/xena\%20swmata.pdf (Accessed Nov 2018).

2. Hong KH, Kim YJ, Chun SW, et al. Risk factors for complications associated with upper gastrointestinal foreign bodies. World J Gastrenterol 2015; 21(26): 8125-31.

3. Webb WA. Management of the foreign bodies of the upper gastrointestinal tract: Update. Gastrointest Endosc 1995 Jan; 41(1): 39-51.

4. Garrido Serrano A, Fernández Álvarez P. A foreign body in the small bowel: a rare entity of acute abdomen. Rev EspEnferm Dig 2018;19:111.

5. Izumi J, Satoh K, Iwasaki W, et al. Small Bowel Obstruction Caused by the Ingestion of a Wooden Toothpick: The CT findings and a Literature Review. Intern Med 2017; 56(6): 657-60. 
6. Kurer MA, Davey C, Khan S, et al. Colorectal foreign bodies: A systematic review. Colorectal Dis 2010; 12(9): 851-61.

7. Benedikt V, Kovalevski A. Foreign body of the appendix as a cause of acute appendicitis. Klin Khir 1988; (4): 64

8. Green S, Schmidt S, Rothrock S. Delayed appendicitis from an ingested foreign body. Am J Emerg Med 1994; 12(1): 53-6.

9. Reddy E.R. Retained lead shot the appendix. J Can Assoc Radial 1985; 36(1): 139.

10. Rodriguez-Hermosa JI, Codina-Cazador A, Ruiz B. Management of foreign bodies in the rectum. Colorectal Dis 2007; 9(6): 543-8.

11. Gouvas C. Accidents and Mass Destruction, Causes, and Treatment. Edition of the Greek Red Cross, 2000.

12. Valetto L, Gargalo C. Intra-abdominal needle: medical malpractice? Forensic Sci Int 2009; 191(1-3): e11-3.

13. Schulz D, Mohor GS, Solovan C. Unusual foreign body in the sigmoid colon, chronic alcohol abuse and Fournier gangrene: A case report. Clin Interv Aging 2015; 10: 673-7.

14. Gardikis S, Kabouri A. Principles of Pediatric Surgery \& Pediatric Urology. Hellenic Academic Libraries Association, Athens; 2015.

15. Cheng W, Tam PK. Foreign-body ingestion in children: experience with 1,265 cases. J Pediatr Surg 1999; 34(10): 1472-6.

16. Litovitz T, Whitaker N, Clark L, et al. Emergency battery-ingestion hazard: clinical implications. Pediatrics 2010; 125: 1168-77.

17. Iwamuro M, Okada H, Matsueda K, et al. Review of the diagnosis and management of gastrointestinal bezoars. World J Gastrointest Endosc 2015; 7(4): 336-45

18. Western C, Bokhari S, Gould S. Rapunzel Syndrome: A case report and review. J Gastrointest Surg 2008; 12: 1612-4.

19. Fawcett EJ, Fawcett JM, Mazmanian D. A meta-analysis of the worldwide prevalence of pica during pregnancy and the postpartum period. Int J Gynaecol Obstet 2016; 133(3): 277-83.

20. Byard RW. A review of the forensic implications of pica. J Forensic Sci 2014; 59(5): 1413-6.

21. Lacey EP. Broadening the perspective of pica: literature review. Public Health Rep 1990; 105(1): 29-35.

22. Jacob B, Huckenbeck W, Barz J, et al. Death after swallowing and aspiration of high number of foreign bodies, in a schizophrenic woman. Am J Forensic Med Pathol 1990; 11(4): 331-5.

23. Kobiela J, Mittlener S, Gorycki T, et al. Vast collection of foreign bodies in the stomach presenting as acute gastrointestinal bleeding in a patient with schizophrenia. Endoscopy 2015; 47 Suppl 1 UCTN: E 356-7.

24. Klein A, Schroder C, Heinemann A, et al. Homicide or suicide? Xylophagia: a possible explanation for extraordinary autopsy findings. Forensic Sci Med Pathol 2014; 10(3): 437-42.

25. Evans DC, Wojda TR, Jones CD, et al. Intentional ingestions of foreign objects among prisoners: A review. World J Gastrointest Endosc 2015; 7(3): 162-8

26. Bisharat M, O'Donnell ME, Gibson N, et al. Foreign body ingestion in prisoners the Belfast experience. Ulster Med J 2008; 77(2): 110-4.

27. Weiland ST, Schurr MJ. Conservative management of ingested foreign bodies. J Gastrointest Surg 2002; 6(3): 496-500.

28. O'Sullivan ST, Readron CM, Mc Greal GT, et al. Deliberate ingestion of foreign bodies by institutionalized psychiatric hospital patients and prison inmates. Ir J Med Sci 1996; 165: 294-6.
29. Blaho KE, Merigian KS, Winbery SL, et al. Foreign body ingestions in the Emergency Department: case reports and review of treatment. J Emerg Med 1998; 16: 21-6.

30. Lee TH, Kang YW, Kim SM, et al. Foreign objects in Korean prisoners. Korean J Intern Med 2007; 22: 275-8.

31. Narjis Y. Surgical digestive emergencies in prisoners, about a prospective study. J Emerg Trauma Shock 2014; 7(1): 59-61.

32. Petrea S, Brezean I. Self-harm through foreign bodies ingestion-a rare cause of digestive perforation. J Med Life 2014; 7(1): 67-74.

33. Volpi A, Laforgia R, Lozito C, et al. Ingestion of foreign bodies among prisoners: a ten-year retrospective study at University Hospital of Southern Italy. G Chirg 2017; 38(2): 80-3.

34. Gill JR, Graham SM. Ten years of "body packers" in New York City: 50 deaths. J Forensic Sci 2002; 47(4): 843-6.

35. Fishbain DA, Welti CV. Cocaine intoxication, delirium and death in a body packer. Ann Emerg Med 1981; 10(10): 531-2.

36. Schaper A, Hofmann R, Bargain P, et al. Surgical treatment in cocaine body packers and body pushers. Int J Colorectal Dis 2007; 22(12): 1531-5.

37. Busch B, Starling R. Rectal foreign bodies: case reports and a comprehensive review of the world's literature. Surgery 1986; 100(3): 512-9.

38. Sauvageau A, Racette S. Autoerotic deaths in the literature from 1954 to 2004: a review. J Forensic Sci 2006; 51(1): 140-6.

39. Patelarou A, Spanoudaki M, Laliotis A. Retained surgical items A threat to perioperative safety in the 21st century? Archives of Hellenic Medicine 2013; 30(4): 467-72.

40. Lincourt AE, Harell A, Cristiano J, et al. Retained foreign bodies after surgery. J Surg Res 2007;1 38: 170-4.

41. Gawande AA, Studdert DM, Orav EJ. Risk factors for retained instruments and sponges after surgery. N Engl J Med 2003; 348: $229-35$.

42. Hariharan D, Lobo DN. Retained surgical sponges, needles and instruments. Ann R Col Surg Engl 2013; 95: 87-92.

43. Gümüş $M$, Gümüş H, Kapan $M$, et al. A serious medicolegal problem after surgery: gossypiboma. Am J Forensic Med Pathol 2012; 33(1): 54-7.

44. Wang C, Cipolla J, Seamon M, et al. Gastrointestinal complications related to retained surgical foreign bodies (RSFB): A concise review. OPUS 12 Scientist 2009 Vol 3, No1.

45. Botet del Castillo FX, López S, Reyes G, et al. Diagnosis of retained abdominal gauze swabs. Br J Surg 1995; 82 (2): 227-8.

46. Lauwers PR, Van Hee RH. Intraperitoneal gossypibomas: the need to count sponges. World J Surg 2000; 24(5): 521-7.

47. Tumer AR, Yasti AC. Medical and legal evaluations of the retained foreign bodies in Turkey. Leg Med (Tokyo) 2005; 7(5): 311-3.

48. Bani-Hani KE, Gharaibeh KA, Yagham RJ. Retained Surgical Sponges (Gossypiboma). Asian J Surg 2005; 28(2): 109-15.

49. Yildirim S, Tarim A, Nursal TZ, et al. Retained surgical sponge (gossypiboma) after intraabdominal or retroperitoneal surgery: 14 cases treated at a single center. Langenbecks Arch Surg 2006; 391 (4): 390-5.

50. Tchangai $B$, Tchaou $M$, Kassenge I, et al. Incidence, root cause, and outcomes of unintentionally retained intraabdominal surgical sponges: a retrospective case series from two hospitals in Togo. Patient Saf Surg 2017 Oct 26; 11: 25. 